\title{
OFICINAS DE CINECLUBE ITINERANTE: COMPARTILHANDO O CINEMA BRASILEIRO
}

\author{
ITINERANT CINE CLUB WORKSHOPS: \\ SHARING THE BRAZILIAN CINEMA
}

Patrícia Ferreira Marassi ${ }^{1}$

Resumo: Por meio da parceria entre os Projetos "Oficinas Culturais 2018" e "Programa Terceira Idade na Universidade" foram desenvolvidas oficinas de cineclube itinerante com as pessoas idosas. O projeto teve como objetivo promover, a partir das experiências audiovisuais nacionais, o conhecimento da produção do cinema brasileiro, assim como o intercâmbio cultural e a reflexão crítica entre os diferentes costumes, crenças, discursos e valores decorrentes das relações sociais na sociedade brasileira. As oficinas foram organizadas em eixos temáticos, focados na transformação social e empoderamento de idosas e idosos, além de, proporcionar um espaço de lazer recheados de conhecimentos e afetos.

Palavras-chave: Pessoas Idosas. Oficinas Culturais. Cineclube Itinerante.

Abstract: Through the partnership between the "Oficinas Culturais 2018" and "Programa Terceira Idade na Universidade" projects, itinerant film club workshops were developed with the elderly. The project aimed to promote, based on national audiovisual experiences, the knowledge of Brazilian cinema production, as well as cultural exchange and critical reflection between the different customs, beliefs, discourses and values resulting from social relations in Brazilian society. The workshops were organized on thematic axes, focused on social transformation and empowerment of elderly women and men, in addition to providing a leisure space filled with knowledge and affections.

Keywords: Elderly People. Cultural workshops. Itinerant Cine Club.

\section{INTRODUÇÃO}

Por meio da parceria entre os Projetos "Oficinas Culturais 2018" e "Programa Terceira Idade na Universidade", oferecidos pela Coordenadoria de Cultura COC/PROEX da Universidade Federal da Grande Dourados (UFGD), foram desenvolvidas oficinas de cineclube de forma itinerante com idosas e idosos de dois

\footnotetext{
${ }^{1}$ Mestre em Psicologia pela Universidade Federal da Grande Dourados - UFGD (2020).
} 
Centros de Referência de Assistência Social- CRAS no município de Dourados, durante os meses de agosto a dezembro de 2018.

A título de reconhecimento, é pertinente apresentar um pouco desses projetos que possibilitaram o delineamento e a realização das oficinas de cineclube itinerante.

O projeto de extensão "Oficinas Culturais 2018” considera essa ação parte fundamental da intervenção cultural da UFGD, no sentido de democratizar o acesso à produção artística na cidade de Dourados, no estado do Mato Grosso do Sul.

Durante o ano de 2018, o projeto selecionou 16 bolsistas para planejar e desenvolver oficinas à comunidade interna e externa da UFGD, pelos quais foram realizadas as oficinas culturais para formação e aperfeiçoamento de diferentes linguagens artísticas e culturais, como Música, Artes Visuais, Dança, Artes Cênicas, Cinema, Literatura entre outras, coordenadas pela Coordenadoria de Cultura COC/PROEX/UFGD.

Através dessa diversidade de atividades desenvolvidas em espaços culturais, dentro e fora da Universidade Federal da Grande Dourados - UFGD, por meio do trabalho coletivo entre alunas e alunos bolsistas e coordenadoras, foram atendidas cerca de 1.000 pessoas da população douradense, de todas idades, independentemente da classe econômica e social.

As atividades oferecidas tinham como propósito, proporcionar o acesso à cultura a todas as pessoas, como também o desenvolvimento das habilidades das/os participantes, incluindo aspectos físicos, emocionais, sociais e cognitivos.

E o "Programa Terceira Idade na Universidade" desenvolve ações de extensão em que têm como público alvo as pessoas idosas, ao mesmo tempo em que manifesta o comprometimento da Universidade Federal da Grande Dourados com a promoção do conhecimento e da cultura, bem como a cidadania e inclusão de todas/os.

Dessa forma, este projeto além de promover atividades para a melhoria das condições de vida e lazer da população idosa, também evidencia a necessidade de seguridade dos direitos elementares, em que se preconiza o processo de empoderamento $^{2}$ destas pessoas, desenvolvendo ações educacionais que reforçam a

\footnotetext{
${ }^{2}$ Considera-se a perspectiva de Empoderamento enquanto conceito teórico e metodológico, e como um instrumento de emancipação por meio de um processo participativo, tanto individual quanto coletivo, além de ser um caminho para a produção de conhecimentos, e de desenvolvimento de práticas na busca por mudanças sociais (BAQUERO, 2012). Assim sendo, segue-se a concepção para além de um conceito, mas
} 
importância da visibilidade social e política desse grupo, bem como a articulação e organização coletiva em favor da defesa dos seus direitos e reivindicação de maior reconhecimento e respeito no cotidiano e na sociedade.

O mesmo programa oferta também disciplinas nos cursos de graduação da UFGD às pessoas com 55 anos ou mais, como também palestras por meio de voluntários da Universidade como servidores Docentes, Técnicos e alunos de Graduação e PósGraduação, e possibilita a participação nas atividades de Cultura e Lazer como as apresentações da Orquestra da UFGD, no FESDOM- Festival de Música, FIT- Festival de Teatro e na MAD - Mostra Audiovisual.

Portanto, a proposta da oficina cultural de cineclube itinerante para os grupos de idosas e idosos nasceu a partir dessa relação dialógica da autora junto à coordenadoria de cultura da Universidade Federal da Grande Dourados e com às coordenadoras dos projetos citados anteriormente.

À vista do exposto, o projeto de cineclube itinerante direcionado às pessoas idosas parte do pressuposto de que a utilização da tecnologia audiovisual possibilita a interação da comunidade interna e externa à UFGD, na mesma medida que oportuniza a troca de conhecimentos acerca da diversidade de filmes e documentários produzidos por brasileiras/os que retratam a realidade do país.

Sobretudo, as trocas que merecem destaque são de afetos, de empatia, de respeito e dedicação com essas pessoas que se esforçavam para estar presente durantes os encontros, cada um/a como sua dificuldade, mas que segundo a fala de uma das participantes "para aprender coisas novas, se divertir, reencontrar uma amiga ou amigo, as coordenadoras do projeto, assistir um filme e comer um lanche gostoso, o esforço vale a pena”.

E foi em busca dessas trocas, desses momentos de aprendizagem e lazer, que os cineclubes surgiram. De acordo com Salles (2015), os cineclubes como meio de comunicação tive início por volta de 1950, os quais são considerados também como um instrumento científico no universo da arte cinematográfica, marcados por discussões políticas, culturais e sociais.

também como uma prática, ou seja, como uma ferramenta emancipatória, de entendimento, conscientização e desenvolvimento sociopolítica com base na coletividade (BERTH, 2018). 
Para a autora, "o movimento cineclubista foi e é historicamente importante para a compreensão de inúmeros fatores relacionada ao binômio cinema/sociedade" (SALLES, 2015 p.2).

Assim sendo, o desenvolvimento dos cineclubes se deu como uma forma de linguagem artística e também como uma das ferramentas pedagógicas que contribuíram para a politização dos seres humanos, assim como para a apropriação e compartilhamento de conhecimentos que auxiliam os indivíduos na conscientização do seu papel social enquanto integrantes de uma sociedade democrática (KLAMMER, FORTUNATO \& MELO, 2015).

Braga (2019) acrescenta que o cineclube é também uma maneira de apresentar a realidade e seu modo de pensar, ao mesmo tempo em que, sua formação e organização, para depois intervir e conscientizar o grupo a respeito da necessidade e urgência de transformação social.

Com base nesses pressupostos, as oficinas de cineclube itinerantes foram pensadas e organizadas em eixos temáticos, nos quais os temas foram escolhidos e construídos com a participação das idosas e idosos, desde o início e no decorrer das atividades, justamente com a intenção de propiciar um espaço participativo e de acolhimento, como uma maneira de estimular o fortalecimento de vínculos entre as/os participantes, bem como a troca de vivências e saberes.

A justificativa das atividades desenvolvidas pelo projeto de cineclube itinerante, está na promoção e integração entre a comunidade interna e externa à UFGD, demonstrando assim a relevância e ampliação destas práticas culturais para além dos espaços acadêmicos, promovendo interações sociais entre os participantes dos grupos, bem como o conhecimento e intercâmbio cultural entre os diferentes costumes, crenças e valores da sociedade brasileira.

A escolha das atividades de forma itinerante foi pensada para atender a um maior número de pessoas idosas que possuem dificuldades para o deslocamento o local onde seria realizada a atividade, não só a econômica, mas também física e de tempo, pois nem todos moravam próximos aos CRAS.

Portanto, o objetivo geral traçado para o desenrolar deste projeto foi de promover, a partir das experiências audiovisuais nacionais, o conhecimento da produção do cinema brasileiro, assim como o intercâmbio cultural e a reflexão crítica entre os 
diferentes costumes, crenças, discursos e valores decorrentes das relações sociais na sociedade brasileira.

E como objetivos específicos, oportunizar a troca de conhecimentos acerca da diversidade cultural pertencente ao Brasil; estimular a análise acerca da realidade local cultural e fomentar práticas transformadoras a partir de exemplos do cinema englobando longas/curtas-metragens, documentários e filmes; enfatizar a relevância do cinema e do debate de seus temas no processo de desenvolvimento da consciência cultural e a condição humana, bem como ampliar as possibilidades de interação entre comunidade interna e externa à UFGD, para além dos espaços acadêmicos.

\section{DESENROLAR DAS ATIVIDADES}

O projeto foi bem recebido pelas coordenadoras dos CRAS, inclusive agradeceram a disponibilidade da UFGD em levar atividades culturais até a população mais carente.

Assim sendo, o delineamento das oficinas de cineclube itinerante foi pensado de acordo com a comunidade participante (envolvendo coordenadoras, aluna e grupos participantes).

Em outras palavras, as atividades foram organizadas para as pessoas idosas, para que os filmes escolhidos correspondessem à demanda trazida pelo coletivo presente nos encontros, promovendo assim desde o início a discussão e a troca de ideias.

As sessões de cineclube foram desenvolvidas concomitantemente com os dois grupos durante a semana, mas em dias alternados nos CRAS.

Todos os encontros ocorriam da seguinte maneira: antes da exibição do filme, eram relatadas as características e a qualidade da obra, bem como dos autores e atores. E após o encerramento da projeção, abria-se o espaço interativo no qual deixava-se, no primeiro momento, que os comentários rolassem livremente, e, a partir das impressões iniciais, era proposto ao grupo a problematização sobre as ideias veiculadas no filme e a verossimilhança dos acontecimentos, sem deixar de lado as interpretações que cada um deles dava a respeito das cenas exibidas no filme.

Deixando o espaço sempre aberto para que as/os participantes pudessem expressar sua concepção, por meio de questionamentos, como: "Será que concordam ou 
não com a mensagem passada pelo diretor? Que argumentos justificam a sua discordância ou concordância?

\section{COMPOSIÇÃO DOS GRUPOS: G1 E G2}

A construção dos grupos se deu a partir do convite nos CRAS, e seguidamente aos grupos de pessoas idosas.

Desde o início, a motivação para o desenvolvimento das atividades foi nítida. As/os participantes foram logo escolhendo os filmes e os dias que poderiam assistir.

Assim sendo, o número total de participantes inicialmente foi de 40 pessoas idosas entre homens e mulheres, porém as/os frequentes foram 37. Em que no Grupo 1 (G1) participavam 24 mulheres e 1 homem, e no Grupo 2 (G2) eram 10 mulheres e 2 homens.

É importante relatar que, seguimos todas as diretrizes estabelecidas no Estatuto da Pessoa Idosa (Lei 10.741/2003), e consideramos as especificidades dos grupos durante os cineclubes, em que se preocupou em adaptar uma linguagem, como sons e imagens, bem como os lanches e cadeiras para acomodação confortável.

Desse modo, as experiências das pessoas ali presentes foram valorizadas e evidenciadas, pois acreditamos que "a velhice, como todas as situações humanas, tem uma dimensão existencial: modifica a relação com o mundo e com sua própria história" (BEAUVOIR, 1990 p.15).

Destacou-se assim, a necessidade da participação e inclusão desses grupos nas atividades desenvolvidas nos CRAS, considerando-os como parte da transformação social da sociedade brasileira, ao mesmo tempo em que, se sentem ativos e ocupam seu tempo com projetos que contribuam direta ou indiretamente para melhorar suas relações sociais no cotidiano.

A partir disso, vale lembrar a respeito da significância dessas atividades para esses grupos, estimulando seu pensamento e criatividade, considerando que nesse momento da vida, as relações e comunicação se tornam mais difíceis, devido ao processo de envelhecimento.

Dificuldades essas, que acabam excluindo essas pessoas de alguns espaços de convívio social e coletivo. Entretanto, ao menos durante nossos encontros, essas 
dificuldades foram superadas e deixadas de lado, fato que facilitou o fortalecimento e desenvolvimento das atividades com os grupos.

Outra característica marcante desses grupos foi a presença majoritária das mulheres idosas viúvas nas oficinas de cineclube. De acordo com Camarano (2003), esse contexto que pode ser justificado pelo processo de "feminização da velhice", ou seja, menor mortalidade das mulheres idosas, em decorrência das condições adquiridas e utilizadas ao longo da vida, como por exemplo o acesso as políticas públicas.

Segundo a autora, as mulheres idosas hoje, são mulheres que, em sua maioria não tinham durante sua vida adulta um trabalho remunerado, e por isso havia e ainda há uma maior busca por trabalho extradomésticos pelas mulheres (CAMARANO, 2003). Situação que as direcionam as atividades oferecidas pelos CRAS de sua região, e com isso incluem-se o acesso a saúde e ao lazer.

\section{VIVÊNCIAS DURANTE OS ENCONTROS}

Sendo assim, no primeiro encontro, iniciou-se a oficina com a discussão sobre o que é cineclube e sua relevância enquanto atividade educativa. Foi observado que muitos das/os participantes desconheciam esse tipo de atividade e ficaram bem contentes pela oportunidade disponibilizada.

Após esse primeiro contato, foi solicitado a todas/os que falassem sobre o que gostariam de assistir, para que as atividades, além de proporcionar conhecimento, fossem também prazerosas.

Com base nas falas, foram organizados três eixos temáticos para serem trabalhados durante as oficinas, são eles:

\section{$1^{\circ}$ eixo: Relacionamentos amorosos, amigos e festa}

Por meio do filme "Chega de Saudade", lançado em 21 de março de 2008, sob a direção de Laís Bodanzky, no qual cinco personagens são frequentadores de um baile de dança na cidade de São Paulo, e ao som de músicas brasileiras e com muita dança, a obra aborda temas como amor e traição, desejo e solidão, amizades e intrigas. 
Posterior à exibição do filme, o diálogo entre as pessoas idosas (17 mulheres solteiras/casadas e 1 homem viúvo) do G1 foi bem interativo, sendo que todas/os participaram expressando seu posicionamento sobre as cenas do filme. A maioria das mulheres disseram que, "assim como no filme, também frequentam bailes" e que "costumam namorar muito". Somente duas disseram que "não participam de festas desse tipo" e que acham "feio quando mulheres ficam dançando com desconhecidos".

Isso demonstra a diferença entre os discursos das participantes, mesmo que com idades parecidas, umas se dizem "mais conservadoras" que as outras. E essa característica foi percebida entre as idosas que sempre foram donas de casa e não tiveram a oportunidade de trabalhar fora e ter uma profissão.

Melo e Thomé (2018) afirmam que essa condição da mulher é considerada estruturante nas relações de poder entre mulheres e homens, ou seja, é decorrente de uma sociedade patriarcal, em que para as mulheres são destinadas somente às atividades não remuneradas e limitadas ao espaço privado (casa), como domésticas e do cuidado, e aos homens o trabalho remunerado e público (fora de casa), em que ficam responsáveis pelo sustento da família.

Federici (2019) relata sobre esse contexto sexista e historicamente assimétrico a respeito dos trabalhos realizados pelas mulheres, no qual as mulheres dedicavam e ainda continuam dedicando a maior parte do seu tempo e saúde na realização de atividades domésticas, ou seja, dos trabalhos considerados por ela como essenciais na reprodução da vida, sem nenhum tipo de reconhecimento ou remuneração financeira.

Conforme a perspectiva da autora, é na reprodução e na organização da vida humana desempenhada e organizada pela mulher, que se fundamenta o sistema capitalista e sexista.

Nesse sentido, é possível compreender as diferentes concepções da construção do papel da mulher entre as participantes, mas que o modelo enquanto mãe, esposa e dona de casa ainda se mantém enraizado na sociedade contemporânea. Bruschini (2007) analisa especificamente a realidade brasileira, e evidencia que a presença da mulher no mercado de trabalho é marcada por avanços, entretanto vem carregada de obstáculos.

Em que de um lado, as mulheres conquistaram o maior acesso aos trabalhos remunerados nos espaços públicos, mas de outro as condições de trabalho são precarizadas, invisibilizadas, desvalorizadas com salários baixos, e a carreira profissional 
continua sendo prejudicada em decorrência do sobrecarga dos trabalhos domésticos e do cuidado que não são compartilhadas entre o casal no cotidiano familiar (BRUSCHINI, 2007).

Entretanto, percebeu-se também que algumas das mulheres idosas presentes nos cineclubes já estão no processo de ressignificação do discurso de mulher como rainha do lar, situação que demonstra conforme a perspectiva de Tiburi (2018), que elas já estão desconstruindo o discurso sexista que obriga a mulher a dedicação exclusiva e gratuita à família, e se reconstruindo como mulheres empoderadas, donas de si e de suas escolhas.

Já no G2, a discussão caminhou para outro lado, pois neste dia só haviam mulheres, que se dividiam entre viúvas, separadas e somente uma era solteira (dados coletados diretamente com elas). Notou-se que a ausência dos participantes homens neste dia exclusivamente, proporcionou um encontro diferente dos demais, porque foi considerado segundo a fala das participantes, "um cineclube das mulheres".

Percebeu-se nesse contexto, a necessidade de elaboração de atividades somente com as mulheres, um espaço de liberdade de expressão entre as mulheres, sem preconceitos machistas ou algum tipo de julgamento por parte dos homens. De acordo com a fala delas, neste dia elas "se sentiram livres para falar de tudo".

Lembrando que neste dia o cineclube foi com o filme "Chega de Saudade" e as cenas destacadas por elas foram as traições amorosas, em que algumas participantes disseram: "é comum ocorrer traição entre um casal", "o homem sempre pode trair e a mulher não" $e$ "a mulher tem que perdoar sempre". Cenas que não foram dialogadas no grupo anterior, possivelmente porque haviam esposos no encontro.

Outro ponto em destaque foi o papel dos homens nos filmes, em que as participantes evidenciaram: "na maioria das vezes os protagonistas sempre são os homens" e "isso também acontecia lá em casa, meu ex-marido queria mandar em tudo, por isso não deu certo", falas que demonstram a identificação do cotidiano das participantes com cenas do filme.

Nesse sentido, esses discursos demostram a existência do processo histórico de subalternidade na vida dessas mulheres, de dominação masculina, da permanência do poder nas mãos do marido. Conforme Scott (1988), essa condição superior e cheia de privilégios vivenciada pelos homens é produzida e garantida pela manutenção da hierarquização naturalizada na relação de construção dos papéis sociais entre os gêneros. 
Em contrapartida, e como uma mudança possível, Barbosa e Rocha-Coutinho (2012) apresentam outra realidade, mas ainda de mulheres brasileiras que vivem na cidade Rio de Janeiro, em que através de uma pesquisa, concluíram que a identidade feminina está se modificando, aos passos lentos, na qual o modelo tradicional de mulheres-mãesprofissionais, tem sido substituído por modelos contemporâneos, em que as mulheres têm construído e assumido novos papéis na sociedade.

Entretanto uma preocupação que permanece na vida de grande parte das mulheres, é com a maternidade, com algumas mudanças, pois é pensada como um projeto de escolha pessoal e profissional, porém somente pelas mulheres e não pelo casal, mas que já demonstra a maternidade como uma opção, e que o trabalho de cuidar dos/as filhos/as não é mais visto como condição definitiva e obrigatória da mulher.

\section{$2^{\circ}$ eixo: Viajando pelo mundo}

Esta oficina foi planejada a pedido do G1, em que gostariam de conhecer lugares ainda desconhecidos por eles. Então, foi organizado um passeio até a Unidade I da UFGD para realizar a atividade através do auxílio de uma ferramenta da internet, o Google Earth (esta oficina foi realizada apenas com o grupo 1; em decorrência da falta de ônibus, não se pôde levar o G2).

Neste dia, viajou-se por Lisboa, Montevidéu, Paris, Japão, Bonito e Londrina. $\mathrm{Na}$ medida em que se chegava em cada uma destas localidades, foi pedido para que explicassem o motivo da curiosidade de cada um. E os comentários foram bem diversos, como por exemplo: porque tinham "parentes que moravam nestes lugares", porque desejam "viajar e conhecer pessoalmente cada detalhe das cidades", e também foi falado sobre o "desejo de viajar pelo mundo" e "essa é a única oportunidade de viajar, pois infelizmente esse é mais um dos sonhos que não vou conseguir realizar por cauda das minhas condições econômicas e de saúde”.

Este último comentário foi o mais significativo, pois era visível o desejo da participante em viajar, mas que entre outros sonhos este somente seria mais um a que ela não teria acesso, considerando sua idade, sua saúde e a falta de recurso econômico. Essa é uma das falas bem comuns entre as pessoas idosas, que estão no processo de 
envelhecimento, pois de acordo com Moraes (2008), o envelhecimento individual é decorrente do tempo de vida e dos cuidados com a saúde.

Para o autor, esse processo pode ter efeitos negativos ou positivos de acordo com as condições de vida e trabalho de cada pessoa, que influenciam diretamente o organismo, o psiquismo das pessoas idosas.

\section{$3^{\circ}$ eixo: Família, Trabalho e a Condição da Mulher}

Estas temáticas foram trabalhadas com os dois grupos (G1 e G2) por meio do filme de um dos comediantes mais populares do cinema brasileiro: Amácio Mazzaropi.

Em virtude das cenas do filme, muitos disseram que se identificaram com a rotina de vida da família do Mazzaropi, com as divisões de trabalhos, com a condição da mulher, mãe, esposa e dona de casa (assunto que se destacou novamente), a soberania do pai sobre a escolha das profissões da filha, que sonhava em ser bailarina e do filho, que lia muito para ser um médico.

Nesse sentido, Hirata e Kergoat (2007), afirmam a urgência da desconstrução do papel da mulher enquanto dona de casa, mãe e esposa, e se posicionam em defesa da justa conciliação/divisão do tempo, das atividades domésticas e do cuidado entre os sexos, ou seja, entre as mulheres e homens da casa. Por esse motivo, as autoras teorizam sobre a Divisão Sexual do Trabalho, criticando a naturalização das atividades domésticas e do cuidado, ao passo que valorizam a relevância desses trabalhos na organização da vida humana, e que assim como um trabalho profissional e remunerado, também exige dedicação de tempo e saúde para sua realização.

Por conta dessa naturalização da construção dos papéis sociais familiares desiguais e sexistas, nota-se a necessidade de se compreender como funciona e de onde surge a divisão sexual do trabalho historicamente que se mantém viva na contemporaneidade, mas principalmente entender que sua base fundamental está ligada às hierarquias de gênero, e que tais divisões modulam as trajetórias de homens e mulheres, na mesma medida que limitam as vivências das mulheres. (BIROLI, 2018).

Em outras palavras, Federici (2019, p.43), afirma que “[...] não existe nada natural em ser dona de casa, tanto que são necessários pelo menos vinte anos de 
socialização e treinamento diários, realizados por uma mãe não remunerada, para preparar a mulher para esse papel”.

De acordo com esse cenário assimétrico, considera-se necessária essa discussão com os grupos participantes do cineclube, como uma forma de demonstrar a importância da compreensão da disparidade de gênero nas relações sociais, tanto no cotidiano familiar como no âmbito profissional.

Saffioti (2013) reconhece que descortinar esse contexto assimétrico nas relações entre mulheres e homens envolve compreender como se dá a reprodução social, cultural e histórica concatenada com o sistema reprodutivo econômico capitalista, elementos estes considerados por ela como responsáveis pela manutenção de todo esse sistema desigual assim como da herança histórica de submissão da mulher ao homem. Mas, no geral, o modelo de família não foi tão criticado, acredita-se que por ser um modelo seguido pela maioria das/os participantes, considerando a idade e contexto vivenciado por cada um.

Com base na concepção do Mazzaropi, protagonista do filme, a menina (filha) deveria se casar e arrumar um marido para sustenta-la, já seu filho tinha que ser jogador de futebol e ganhar muito dinheiro. Segundo a perspectiva de Curado (2008), mesmo com algumas mudanças nas relações familiares, política, e de trabalho envolvendo a categoria Mulher, a condição desta ainda continua inferior e desigual à dos homens, uma vez que os trabalhos de cuidado e domésticos até o momento são destinadas às mulheres.

Essa assimetria nas relações de trabalho entre mulheres e homens, assim como na divisão das tarefas, nas palavras de Souza-Lobo (1991), são formas de organizar a desigualdade e subordinação das mulheres.

Acredita-se que mesmo o filme sendo bem antigo e de acordo com a época que foi gravado, o modelo de homem e mulher que predominava era extremamente conservador e patriarcal. No entanto, observou-se durante as discussões, algumas críticas, mas não afirmaram se seguem ou não esse modelo em casa, principalmente a respeito da educação dos filhos.

Em contrapartida, ao posicionamento das participantes, as discussões que ocorreram sobre esses temas não se deram de forma opressiva, mas sim com a intenção de questionar o passado, e, ao mesmo tempo, evidenciar tudo o que já foi conquistado pelo empoderamento das mulheres. Conforme Fraccaro (2018), sabe-se que, ao longo da 
história, as mulheres têm lutado e feito sua própria história sempre em favor da equidade nas relações entre os gêneros.

\section{CONSIDERAÇÕES FINAIS}

É imprescindível dizer que o andamento das oficinas de cineclube itinerante evidenciou a relevância da cultura popular e costumes brasileiros, a partir das experiências audiovisuais oriundas dos filmes exibidos concatenadas com as narrativas de vida compartilhadas pelas/os participantes dos grupos, considerando sempre as potencialidades individuais e do coletivo.

Desse modo, as oficinas de cineclube proporcionaram um contexto social interacional e reflexivo mediante uma linguagem horizontal e libertadora, considerandoos sempre como seres sociais e históricos, bem como o saber local.

Sendo assim, ao longo das atividades, percebemos a motivação dos grupos e o pertencimento com os CRAS, o que promoveu a integração entre as/os participantes e, ao mesmo tempo, a construção de uma rede de apoio e convívio comunitário.

Nosso comprometimento direcionou-se, portanto, em questionamentos acerca das perspectivas de mundo e seus discursos que influenciam diretamente as relações sociais e familiares, bem como na transformação social dos envolvidos nas práticas, desde coordenadoras dos CRAS até as/os participantes ativos, além de proporcionar à comunidade de idosas e idosos momentos de lazer, recheados de conhecimentos e afetos.

\section{REFERÊNCIAS}

BAQUERO, R. V. A. Empoderamento: instrumento de emancipação social? - uma discussão conceitual. IN: Revista Debates, Porto Alegre, 2012. V. 6, n. 1, p.173-187, jan.-abr. Disponível em: http://www.seer.ufrgs.br/debates/article/viewFile/26722/17099. Acesso em 13, maio 2019.

BARBOSA, P. Z., \& Rocha-Coutinho, M. L. Ser mulher hoje: a visão de mulheres que não desejam ter filhos. Psicologia \& Sociedade, 2012, 24(3): 577-587. Disponível em: http://www.scielo.br/pdf/psoc/v24n3/11.pdf. Acesso em 18, maio 2019.

BEAUVOIR, S. de. A velhice. Rio de Janeiro: Nova Fronteira, 1990.

BERTH, J. O que é empoderamento. Belo Horizonte (MG).: Letramento, 2018. 
BIROLI, Flávia. Gênero e desigualdades: os limites da democracia no Brasil. São Paulo: Boitempo, 2018.

BRAGA, D. Opinião Cineclube: cinema como pedagogia de luta. Brasil de Fato. Recife (PE), 2019. Disponível em: https://www.brasildefatope.com.br/2019/05/29/opiniao-orcineclube-cinema-como-pedagogia-de-luta. Acesso em 03, junho 2020.

BRASIL. Estatuto do idoso: lei federal n ${ }^{\circ}$ 10.741, de 01 de outubro de 2003. Brasília, DF: Secretaria Especial dos Direitos Humanos, 2004.

BRUSCHINI, M. C. A. Trabalho e gênero no Brasil nos últimos dez anos. Cadernos de pesquisa, 2007. 37.132: 537-572. Disponível em: http://www.scielo.br/pdf/cp/v37n132/a0337132.pdf. Acesso em: 13, agosto 2019.

CAMARANO, A. A. Mulher idosa: suporte familiar ou a gente de mudança? ESTUDOS AVANÇADOS, 2003, 17 (49). Disponível em: https://www.scielo.br/pdf/ea/v17n49/18396.pdf Acesso em: 08 junho 2020.

CURADO, J. C. Gênero e os sentidos do trabalho social. Campo grande: UCDB, 2008.

FEDERICI, S. O ponto zero da revolução. Editora Elefante, 2019. Edição do Kindle.

FRACCARO, G. Os direitos das mulheres: feminismo e trabalho no Brasil (1917-1937). Rio de Janeiro: FGV editora, 2018.

HIRATA, H., \& KERGOAT, D. Novas configurações da divisão sexual do trabalho. Cadernos de Pesquisa, 2007 v. 37, n. 132, set./dez. Disponível em http://www.scielo.br/pdf/cp/v37n132/a0537132.pdf. Acesso em: 05, abril 2020

KLAMMER, C. R., FORTUNATO, J. \& MELO, R. A importância do cinema por meio do cineclube na escola. Educere. PUC-PR, 2015.

MELO, H. P. de \& THOMÉ, D. Mulheres e poder: Histórias, ideias e indicadores. Rio de Janeiro: FGV Editora, 2018.

MORAES, E. N. Princípios básicos de geriatria e gerontologia. Brasília: Coopmed, 2008.

SAFFIOTI, H. I. B. A mulher na sociedade de classe: mito e realidade. 3. ed . São Paulo: Expressão Popular, 2013.

SALES, P. C. O movimento cineclubista brasileiro e suas modulações na recepção cinematográfica. Anais do XXVIII Simpósio Nacional de História. Lugares dos historiadores. Velhos e novos desafios. Florianópolis, 2015. Disponível em: http://www.snh2015.anpuh.org/resources/anais/39/1434480954_ARQUIVO_Omovime nto cineclubistabrasileiroesuasmodulacoesnarecepcaocinematografica.pdf. Acesso em: 02/03/2019. 
SCOTT, J. W. Gender and the Politics of History. New York: Columbia University Press, 1988. pp. 28-50.

SOUZA-LOBO, E. A Classe Operária tem dois sexos. São Paulo: Edit. Brasiliense, 1991.

TIBURI, M. Feminismo em comum: para todas, todes e todos. Rio de Janeiro: Rosa dos Tempos, 2018. 